\title{
2006-461: SOLAR ENERGY EDUCATION FOR ENGINEERING STUDENTS IN A MIDDLE EASTERN COUNTRY - AN APPROACH
}

\section{David Dalton, The Petroleum Institute}

David F Dalton is a senior lecturer in Communications at the Petroleum Institute in Abu Dhabi. He has sixteen years experience of teaching language and communications at universities in the UK, Spain, Mexico and the UAE. He also has extensive experience of curriculum design and educational management. His current work focuses on teaching a range of practical, synthesized communications and research skills to students who will later work in the oil and gas industry as engineers, managers and administrators.

\section{Isoroku Kubo, The Petroleum Institute}

Dr. Isoroku Kubo is an associate professor at the Petroleum Institute in Abu Dhabi. He holds $\mathrm{Ph}$.D. degree from the Mechanical and Aerospace Engineering department at Cornell University and has taught several mechanical engineering courses for 7 years. He is an internationally recognized authority for his work in the solar energy-driven power which won him and his team at Cummins the prestigious R\&D 100 award. Before starting his academic career, he worked in the automotive industry for many years including 17 years at Cummins Engine Company (USA). 


\section{Solar Energy Education for Engineering Students in a Middle Eastern Context-an approach.}

\section{Introduction}

The purpose of this paper is to describe a currently ad-hoc approach to teaching United Arab Emirates engineering students about alternative sources of energy. In tertiary institutes in the USA, Australasia, Europe and elsewhere, such a focus would be a given in the curriculum as the issue is a well-established one. In this region, it is relatively new, as the concept of inexhaustible oil has long dominated. Awareness (not interest) among the student body and the broader society has consequently not been substantially developed.

In the context of depletion of non-renewable energy sources, increasing concern about global warming, economic considerations and a shift of focus within the oil and gas industry itself, not only is such an initiative relevant, but (we advocate) should be a planned and programmed part of our curriculum development process. It should be both cross-curricular and interdisciplinary and project based in nature. Already, engineering programs in the Gulf region such as those in King Faisal University of Petroleum and Minerals in Saudi Arabia and Kuwait University include ASE issues and components in their curriculum, albeit at differing stages of development.

It is further significant in our context in that we are committed to developing behavioral competencies outlined by our sponsor, the national oil company- teamwork, organization, planning; time-management etc. ASE projects lend themselves to the kind of teamwork and project management which utilizes these skills and is so common in the engineering and energy industry. In addition, as we are a foreign language institute, they provide a clear context and framework for the application and development of the students' language skills.

\section{Background}

The Abu Dhabi National Oil Company (ADNOC) operates in all areas of the oil and gas industry. It was established in 1971 and has steadily widened its endeavors through its subsidiaries, establishing an integrated oil and gas industry in Abu Dhabi. The Company manages and oversees oil production of over two million barrels a day and is among the top ten oil and gas companies in the world. It has substantial and impressive upstream and downstream operations in transportation, shipping, marketing and distribution.

Five years ago, ADNOC announced the establishment of The Petroleum Institute, in Abu Dhabi. The decree, establishing the Petroleum Institute, provides for an entity that will bring together the best from education and industry to create a world class regional center for engineering, applied science and research.

ADNOC and its partners signed a ten-year agreement with Colorado School of Mines to provide leadership in programs and curriculum design, with the goal of achieving international accreditation for the Petroleum Institute. 
The Institute is managed by a board including partners from TotalLFinaElf, JODCO (Japan Oil Development Co.), Shell and BP. Ultimately we are responsible to the Abu Dhabi National Oil Company (ADNOC) which is our parent company and sponsor, and will receive/employ all graduating students. The goals of the Institute include:

- Educating U.A.E. citizens and non-citizens in fields of engineering that will serve the ongoing needs of the oil and gas industry in the Gulf region.

- Fostering the creation of knowledge that is of benefit to the regional oil and gas industry, and that continually enriches its academic programs.

- Operating as an educational and research hub.

- Serving the on-going needs of industry and practicing professionals for continuing education in the fields of oil and gas technology.

The Institute offers five baccalaureate degree programs: chemical engineering, petroleum engineering, petroleum geosciences engineering, mechanical engineering and electrical engineering. As the undergraduate programs mature, the PI will eventually evolve into a fullyfledged research and educational institution providing programs leading to Master of Science and Doctor of Philosophy degrees. Planning is now underway for graduate and research programs.

For some time now there has been a growing concern in our industry to ensure a range of skills and competencies amongst prospective employees that go well beyond the content-specific knowledge base appropriate for a particular field. Today there is more of an emphasis on the whole person, exemplified by concerns that students exiting institutes such as ours should be able to call upon a range of competencies of a more behavioral nature.

Recognizing that the most immediate and dominant product of the Petroleum Institute will be baccalaureate graduates, the institutional educational goals for baccalaureate degrees identify attributes that reflect this whole-person development of the graduating student. This is stated in our graduate profile which includes the following description:

- The graduating student will appreciate the critical role played by verbal, written and graphical communications in engineering practice and project management, and will have the corresponding skills to communicate with a range of audiences, and the skills to employ information technologies where appropriate.

- The graduating student should acknowledge that technologies, economies and societies are in a continuous state of evolution, and should therefore have the flexibility to manage a career path that changes over time, and that is supported by life-long learning, critical thinking, teamwork, leadership and the ability to span several disciplines.

- The graduating student should understand the global nature of modern engineering and business, and in order to succeed in this international arena the student should have an awareness of customary practices in different countries and the influence of diverse cultures.

Implied by this background is an approach which should go beyond the confines of a more traditional engineering education and in the current climate increasing our students' awareness of solar energy and having them explore energy alternatives is a logical element of this. 
As stated in the introduction, our current approach is ad-hoc and has arisen partly from a concern amongst some faculty that there is a need to educate our students about current and future utilization of non-fossil fuel energy sources. This is a reflection of a broader global concern. One obvious factor here is increasing worry over global warming and environmental issues. At the annual meeting of the World Economic Forum in January 2005, the keynote speaker (British Prime Minister Tony Blair) identified climate change as the organization's top priority for the coming year. Emissions from burning fossil fuels is an established high causal factor in this problem. Re-shaping thinking about energy use and alternative sources is legitimate and has an added sense of urgency in such a context. In a CNN poll carried out in November 2005, some of the most recurring common concerns expressed were pollution and global warming and depletion of natural resources. This echoed concerns in a similar poll carried out by the same organization in April 2005.

Environmentalists have welcomed plans by the Shell oil company to invest vast sums in wind and solar energy over the next five years. It has plans to spend US\$1bn on research and development. BP is also looking ahead. In 1999 it acquired the solar company Solarex, giving BP Solar 20 percent of the global market share. "We don't define ourselves as an oil company," Kathy Leech, BP Communications Director for the U.S, explained. "We define ourselves as an energy company. We are looking twenty to thirty years into the future and trying to figure out what the energy sources will be, though we don't know if it will be hydrogen or solar." [1]

Depletion of fossil fuels is another issue which should lead us to think of broadening our focus to look at other energy sources and educate our students about these. The jury is still out on any definitive data on this question and opinions tend to be informed by the traditional polarization of the optimistic or pessimistic scenario. What we could agree on is that the whole concept of depletion is on the table in the $21^{\text {st }}$ century in a way that it never has been before. Exhaustion of existing fields clearly is a problem as evidenced by the current status of the Burgan field in Kuwait, the world's second largest. Further, the question of depletion is also related to costs as evidenced by the recent re-opening of the nuclear debate in the United Kingdom. Nate Lewis at a Cal tech lecture in May 2005 stated that "perhaps the price of fossil fuels will naturally rise due to supply/demand economic forces as we continue to exhaust the supply of these fossil fuels" [2] As stated above, there has been growing interest in the oil and gas industry in research and development into alternative sources of energy from solar to hydrogen cell. With prices of solar panels falling in this country and abundant sunlight, there is increasing interest in the UAE in such alternatives. Further, The UAE has always been at the forefront of environmental concerns in this region.

An additional issue for us at the PI is a focus on teamwork and project management. Teamwork and projects are fundamental dynamics and processes in the context of engineering. Behavioral competencies form a significant focus in our teaching. We draw these from the ADNOC CAMS matrix. See appp 2.

Research and development initiatives of the kind we are involved in, lend themselves to projects and teamwork. Further discussion of this will take place in the following section. 


\section{Approach}

We currently have a number of focuses on alternative energy within different programs in the Institute, but no institutionally agreed integration of these into our formal curriculum. It should be remembered that we are a relatively young institute and that there is no established curriculum tradition of exploring and working with alternatives to fossil fuels. What follows is a description of our current practice.

Foundation program

The pre-university foundation program prepares students for entry into the freshman year. It focuses on developing the students' skills in English, mathematics, science and computers. It is an English medium (foreign language) program which seeks to develop student's knowledge in these areas to a level of proficiency consistent with entry into the degree programs.

Towards the end of the program, the students are involved in an eight- week, team-based project related to Alternative Sources of Energy (ASE) culminating in a technology conference where the teams display a brochure they have created relating to the functioning and benefits of their chosen ASE and answer questions from the attendees.

The first part of the project relates to information input, schema building and team building. Students study core texts and listen to lectures related to renewable sources of energy, comparative advantages and disadvantages and work with a variety of comprehension and text exploration exercise to ensure understanding of the key concepts and language (it must be remembered that our students are foreign language users). From this input, they make various sets of notes and synthesize these into a multi-paragraph text describing the function and benefits of ASE in general. They are then involved in a classroom seminar taking a comparative view of the various examples of ASE having identified criteria for this task.

Having developed a body of knowledge and understanding and the language to express this, they then review a further range of texts and select a single ASE they wish to investigate in more detail. They then develop a second text focusing on the process and viability if their chosen ASE and design a graphic from this depicting the key information related to their source. From this, they produce a hard copy or electronic poster for display and discussion. Some time is then spent analyzing the layout and language of brochures depicting ASE and the students are then given the task of designing one. They are then charged with setting up a stand displaying the written texts and graphic illustrations of the ASE for the technology conference mentioned at the start.

Apart form the language and knowledge development, there is a project management and teamwork approach underpinning the classroom dynamic. As mentioned previously, such competencies are a significant element of our students' growth. In the foundation program, the students are introduced to very basic GANTT charts for time management and planning. They will use these again in a more developed form in the Freshman Communications program and STEPS. 
Freshman Communications.

This program is a two-level one building a knowledge of quantitative and qualitative research in order to communicate findings through a variety of different media. It aims to help students develop 'new' thinking on a chosen area of investigation.

Students therefore move from secondary research derived from literature reviews and case studies to primary research through surveys, interviews and observations having generated their own research question. One of the options for investigation in the second level of the program is always solar energy. Again, students work in teams. From a topic area such as: "Examine the feasibility of implementing solar power panels on one PI building", students develop a research question and begin a search of existing research to inform their thinking. They determine the scope of the project and produce a research report of their findings, including discussion and recommendation.

For example, a report produced by one of the teams last semester tackled this question by looking at the feasibility of using solar panels to power one of our student dormitories. In order to do this, the team looked at logistical problems of space in terms of area and numbers of panels required to meet consumption, cost analysis including how much sunlight would actually hit the panels throughout the year in order to be converted into electricity, per KW cost compared to current costs, capital outlay and projected costs and savings over a thirty-year period.

Their research and calculations demonstrated that such an initiative would be realizable. The students then generated a multi media presentation to demonstrate the feasibility of their findings, including self-made documentary video input and a to-scale model of one of the student dormitories powered by appropriately scaled down solar panels. They could have chosen a much narrower scope and purpose, but were enthused by the topic and the challenge presented by the investigation. As future engineers, they could see the practical value of such a piece of work... As concerned young people in an age of changing energy needs and environmental concerns, they could see the intrinsic and social value of ASE initiatives. Again, the project management, organization, planning and teamwork elements were a significant factor in the success of the project.

\section{STEPS Program and Senior Design Program}

The STEPS II program is mainly taken by juniors in all five disciplines of the engineering programs we offer at the PI. During the course, students pursue a specific project a professor assigns for all the students in the class. There is a competition amongst teams. Grades are assigned to students based on the performance as a team and as an individual. Weight assignments to the final grades for various steps in the program are given at the beginning of the semester and are distributed more or less evenly throughout the program. Rubrics for various milestones during the semester are also given. These milestones include project clarification, conceptual design, detailed design and the final report. Some milestones are marked by oral presentations by students. STEPS programs are organized and run by an English faculty and an engineering faculty acts as a technical advisor and as a client for the project. 
This year, as a project, design and manufacturing of a dual axis solar tracking system was selected. Three teams with five students each were competing in the course. Some examples of their final design were shown below. The originality of the design is also one of the criteria for the evaluation. All teams came up with several different concepts for the mechanism and applied a decision matrix to select their final concepts.
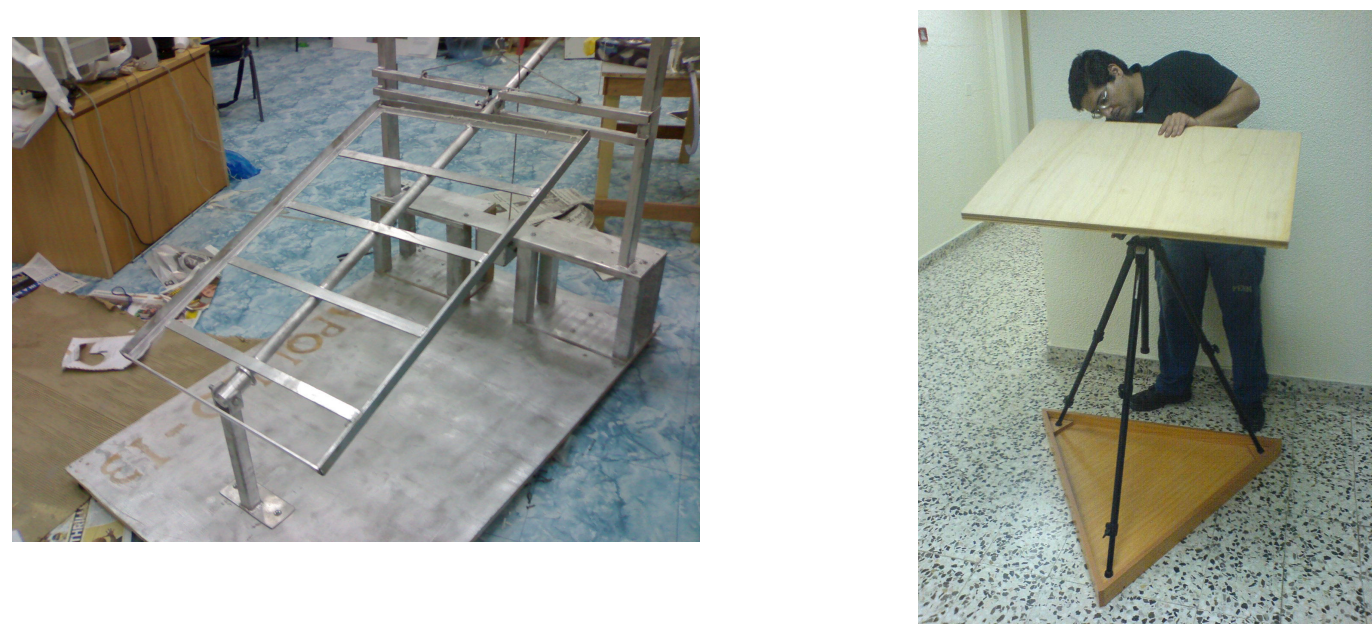

Figure 1. Examples of Students' Designs of Sun Tracking Mechanisms for Solar Panels

Detailed designs for the final concepts were drawn and prototypes were made. At the end of the semester, students demonstrated the capability of their units.

This year, as one of the projects for the senior design course, "a design of a PV solar energy system and its real world application" was selected. Three senior students were assigned for the project and just completed the first phase of the 2-semester project. They have researched past tracking mechanisms designed by various engineers and came up with their own unique design and planned the detailed application for its system. Their work is the culmination of the four year study they received at this institution. They used a computer program to complete the detailed design of the system and performed force and stress analyses as well as an economic analysis to justify the use of the tracking mechanism in this country as compared to a stationary solar panel system. These are currently the main curriculum contexts within which ASE education is taking place.

Clearly solar energy is a natural option here, for the simple reason of the availability of sunlight throughout the year. As future engineers in the energy industry in this country it is even more logical and pressing for our students to be aware of ASE and to be both investigating and developing skills and knowledge within this context.

\section{Recommendations}

Given the initiatives already taken in the Institute and some of the arguments already laid out in the paper, we suggest that it is a logical and necessary part of our institutional curriculum development to take a more planned and systematic approach to the integration of ASE education into our programs and courses. 
Because of the above, we do not need to reinvent the wheel. Rather we need to take an integrated and synthesized view of our existing provision and introduce some further preparation and developmental links. This partly involves making our different provisions explicit and placing them within a framework of an approach which addresses why we feel it is important for our incipient engineers to be informed, educated and skilled within the context of this technology and knowledge.

Courses need to be developed which focus on the rationale for use, history, environmental impacts and economics of ASE. Focus should be given to contemporary developments and future possibilities. Such a framework could be introduced in the initial semester of our freshman program. It could also involve interdisciplinary teams of instructors and students.

Opportunities should then be mapped into the curriculum in our programs where students can carry out further investigation into ASE, applying knowledge and skills they are developing within the context of our majors. This could operate in a cross-discipline manner and again, utilize inter-disciplinary teams. An ASE across the curriculum approach is suggested as this would avoid any marginalization of the theme and confirm to the students and faculty that alternative energy is a priority for the Institute and our parent company.

In line with the above, the practice of team research and design projects should be extended and developed. This could work in parallel with an AE lab provision as offered at other technically oriented institutes and a growing part of our activities here [3].

We are in a position as an institute to take a leading role in this region in the development of ASE education, practice and design. We have already come a long way in putting on stream initiatives of the kind described above. We now need to take a more planned view of the future development of the growth of our curriculum with respect to ASE.

\section{References}

[1]Kathy Leech.Columbia Political Review. May 2004

[2]Nate Lewis. Scientific Challenges in Sustainable Energy Technology. Lecture. Caltech. May 2005

[3] Lawerence Technological University

http://www.ltu.edu/engineering/mechanical/alt energy course3.asp 